\title{
How Does the Booming Short Video Affect Attention Economy?
}

\author{
Hairong Sun ${ }^{1 *}$, Dennis Sawyerr ${ }^{2}$ \\ ${ }^{1}$ Beijing Information Technology College, Beijing 100015, China \\ ${ }^{2}$ Citizens Advice, London E5 9JB, UK
}

\begin{abstract}
The 21st century is the era of new media. We-media, social media, short videos have emerged one after another. Not only have they changed the form of media, but also they have brought tremendous changes in terms of media functions, communication methods and communication relationship etc. Focused on the development of short video platforms in China in the last decade, this essay analyzes the impact of short videos on society, economy, and humanities. Also, it aims to propose a solution to the problem "how to make good use of the scarce resource of attention and truly realize the attention economy".
\end{abstract}

Key words: Short video; New media; Live-streaming sales; Attention economy

Publication date: April, 2021; Publication online: 30 April, 2021

*Corresponding author: Hairong Sun, sunhr@bitc.edu.cn

\section{Introduction}

The 21 st century is the era of new medias which are facilitated by internet information process. With the help of wireless communication networks, satellites, and terminals such as computers, mobile phones, digital televisions, new medias provide users with information and entertainment services in a revolutionary way. It is not only about high tech or science, it is closely related to social relation of production, social structure as well ${ }^{[1]}$. In the past 10 years, short video platforms have sprung up in China. Among them, Kuaishou, Douyin are the very eye-catching ones. Particularly, 2020 has seen the eruption of short videos. During the new coronavirus epidemic, people's activities were restricted, and shopping, entertainment depended heavily on mobile phones and online selling. As a result, 2020 became the year of the outbreak of short videos, which has revolutionized the life of whole society. As the idea of "mobile first" and "video first" gains momentum, there came a new way to entertain people as well as sell goods and do publicity for companies, cities. Internet celebrity anchors such as Wei Ya, Luo Yonghao and Li Jiaqi are going viral. Agricultural things sold by the county magistrate are becoming a fashion. Cities are receiving stunning attention with the mayors using short videos to build on its image. People are busy posting and sharing things with others. "Attention economy" is flourishing.

\section{Definitions of "attention economy" and "short video"}

In 1997, American author Michael H Goldhaber first put forward the concept of "attention economy" in his papers, using words like "attention shoppers" and "attention economy and net". As Goldhaber pointed out, in digital world, what is scarce is not material thing, not information but attention. And the scarcity of attention means that it can be turned into wealth. Attention is more important than money ${ }^{[2]}$. The attention economy comes with it its own kind of wealth, its own class divisions- stars vs. fans - and its own forms of property, all of which make it incompatible with industrial economy.

"Short video" refers to the video that is played on new media platforms at a high-frequency, which is suitable for watching on mobiles at one's leisure. Its content is all-encompassing, including small skills sharing, humorous and witty talks, fashion trends, creative advertising, mini-lecture etc. Short and concise, but informative and interesting are its features. Normally, it's length ranges from 


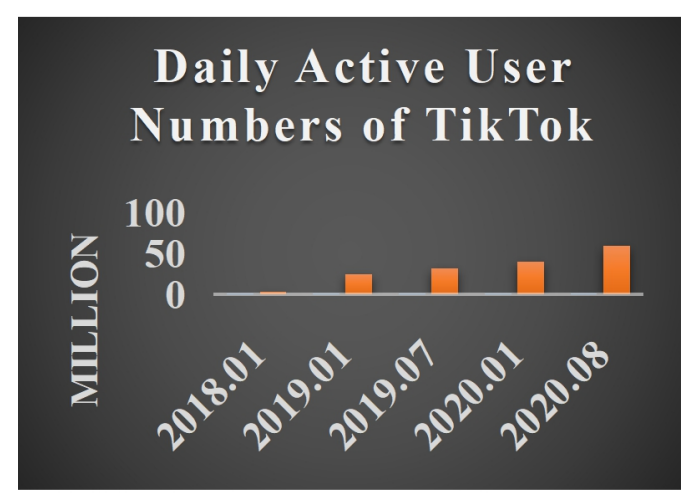

Figure 1. Daily active user numbers of Tik Tok

a few seconds to a few minutes. In addition, it is low cost and has low threshold. The producing process is simple and does not require specific equipment. It can be re-tweeted only if the user registers.

\section{Development of short video in China}

In the last decade, short video giants such as Kuaishou and Douyin have emerged in China's new media market. According to the statistics of iiMedia Research, the scale of China's short video market has reached 140 billion RMB.

Born in March 2011, Kuaishou was originally a mobile application for making and sharing GIF pictures. In November 2012, Kuaishou transformed into a short video community where users can record and share their lives. In April 2017, Kuaishou had more than 500 million registered users, 65 million daily active users, and an average of millions of short videos uploaded daily. In November 2017, its total number of registered users has exceeded 700 million, the number of daily active users has exceeded 100 million, and more than 10 million new video contents were generated daily. In March 2020, its monthly active users exceeded 44 thousand million.

The promising short video market has attracted more participants and competitors. In September 2016, "Today's Toutiao" launched Douyin ( version abroad is Tic Tok ), a music short video community platform. On Douyin, people can choose music and songs, and shoot short music videos of their own. During the 2018 Spring Festival, Douyin's daily active users rose from less than 40 million to nearly 70 million. In June 2018, Douyin's domestic daily active users exceeded 150 million, and monthly active users exceeded 300 million. In mid-July, Douyin had more than 500 million monthly active users worldwide. In March 2020, its monthly active users reached 51 thousand million, showing an increase of $14.6 \%$ than its previous period (Figure 1). Among them, $40 \%$ users are in the age of $24-30^{[3]}$.
From the rise of Kuaishou and Douyin, we can see a tremendous change is undergoing in mass communication. In the $21^{\text {st }}$ century, the term "audience" is a combination of information producer and consumer, namely "prosumer". Based on the Web 2.0, the new media enables everyone to create and disseminate content on their own will ${ }^{[4]}$. Powered by new media, the platforms are busy cashing the flow.

\section{Functions of short video platform}

\subsection{Lighting up life and recording daily life}

In the sea of short videos, there are grassroots' records of life along with real-time interactions between Internet celebrities and fans. The show time is no longer a privilege of celebrities. With short videos, ordinary people can also have their show. Here, people can be the true self, watch what they like, and talk what they like with people of same mind; view a bigger world and be viewed by the world. Su Hua, CEO of Kuaishou, noted that Kuaishou would act as a museum of records, in which people can learn about China.

\subsection{Increasing publicity and building public image}

In addition to sharing one's life, short video also contributes a lot in terms of publicity of a company, a city or a country.

In 2018, Press Center of SASAC (State-owned Assets Supervision and Administration Commission) signed a strategic cooperation with Douyin, and the first batch of 25 central enterprises (including China Nuclear Power, Aerospace Science and Industry, and Aviation Industry, etc.) entered Douyin. The day before the official signing of the cooperation, the News Center opened its account "State-owned Xiaoxin" in Douyin and released its first video, which was played more than two million times in less than 12 hours, and received over 110,000 likes and 150,000 follows.

In 2019, China Daily launched a global short video contest "@China". It received about 430 thousand works from home and abroad, covering the great achievements of China in the past 70 years, revealing a vibrant, peace-loving, modest Chinese people to the world.

In November 2020, Ding Zhen, a Tibetan guy, became a celebrity overnight. From domestic new media platforms such as Douyin and Weibo to local medias, CCTV platforms, and foreign new media platforms, "Sweet Wild Boy" Ding Zhen has topped the hot search rankings on various platforms for many consecutive days. His hometown, Litang county (Ganzi, Sichuan), also came to the spotlight. Being the spokesman of his county, Ding Zhen made his show in 
the Ganzi propaganda film "Dingzhen World", he also had interactions with fans on Weibo@ Ganzi Culture and Tourism as well as other platforms. In the ten days from November 20, 2020, the search volume of "Litang" soared by $62 \%$, which is four times that of October National Day. The "Litang" county wasted no time in this attention economy to boost its tourism by offering free tickets, discounts on hotels, cheaper air tickets, etc. In just 9 days, the reception volume of 13 monitored scenic spots increased by $112.31 \%$ compared to the period last year.

\section{Revolutionizing the presentation and selling of goods}

Unexpectedly, live-streaming sales have become one of the hottest words of 2020 in China. "Live-streaming sales" is a new way for displaying and selling products online. Unlike traditional TV sales, here on the internet chat room, the host or hostess can introduce products in their live show, answering questions and interacting with fans in a more harmonious way. Needless to say, the 2020 corona virus epidemic contributed greatly to the success of live-streaming sales, during which shops were unable to operate and people were restricted from shopping. Online shopping has become a convergence between shops and shoppers. Social media live broadcasts led by internet celebrities such as Wei Ya, Li Jiaqi, Luo Yonghao and others have opened up huge business opportunities. As the "First Lady" of live streaming sales, Wei Ya accomplished a personal sale of up to 20 billion RMB in 2020. In an on-site interview, the host witnessed the miracle of Weiya selling 2000 silver bracelets in 5 seconds. In the pre-sale of Double Eleven in 2020, near 12 o'clock in the night, the number of people in Li Jiaqi and Wei Ya's live broadcast room exceeded 100 million. Many products were sold out within seconds. "Sold out in seconds" has become a hot word regarding live streaming sales. 2020 is known as the first year of the outbreak of short video ${ }^{[8]}$.

\section{Problems and solutions}

While enriching people's lives, producing fat checks, short videos also have caused many social problems.

\subsection{Misuse of attention leads to lost of time and privacy.}

To some extent, the web and the net can be seen as spaces in which we live our lives nowadays and attention is flowing in the opposite direction from those mountains of information. To get some contentment and a sense of control, many of us are selling ourselves far too cheap. "We watch a 30 -second ad in exchange for a video; ... we freely pour sentence after sentence, hour after hour, into status updates and stock responses...", its cumulative cost, while hard to quantify, affects many of those things we hope to put at the heart of a happy life: rich relationships, rewarding leisure, meaningful work, peace of mind ${ }^{[5]}$. When using a free online service, we ourselves became the product that our behavioral data and the quantifiable facts of us are constantly blended for sale.

What's more, the pan-entertainment phenomenon behind short videos reviews mental impetuousness. In the age of information explosion, people are caught in too much "fast food reading" and are content with too much "shallow \& superficial" experiences of joy.

\subsection{Some short videos are vulgar, and the rights of minor children are damaged.}

Statistics show that more and more minors are becoming addicted to the internet, neglecting their studies. Some are even to be found precocious. On October 31, 2017, a 14-year-old girl posted a pregnancy video in Kuaishou.

Since 2018, in order to be eye-catching, Lady Tang scantily dressed, shot fishing videos while wearing red scarves! The videos were uploaded onto the Kuaishou platform with a viewing of more than 3 million times. However, as is well known, in China, the red scarf is the symbol of the Chinese Youth Pioneers, a corner of the red flag and is associated with revolutionary martyrs. Tang's behavior seriously desecrated the red scarf and caused bad social impact.

On July 3, 2018, TikTok, an overseas version of Douyin, was temporarily banned in Indonesia because of content that had an adverse effect on young people, announced by the Indonesian Ministry of Communications and Information Technology.

Recently, the British government released a national report on children's mental well-being. The study identifies a deterioration in children's feeling of well-being, with an increase in the number of children aged 10-15 and young people aged 16-24 reporting being relatively unhappy over the last decade.

"15-year-olds find it harder to make friends," said school surveys by the OECD, a club of mostly rich countries. Because if your friend is always looking at her phone, it may not matter much whether you are around or not ${ }^{[6]}$. So it can make everyone feel left out, or thwart all intimate connections. Perhaps technology has messed up all young people, even those who abstain from it. 
It is high time that measures should be taken to deal with the above problems. On the one hand, supervision should be strengthened, a clean and upright network environment should be ensured; laws and regulations should be made and deployed. On the other hand, real interpersonal communication should be emphasized. Family time shouldn't be replaced by screen time. After all, VR virtual communication cannot and shouldn't replace face-to-face talk.

To enjoy freedom of speech, everyone must shoulder the responsibility of "gatekeeper", distinguish right from wrong, publicize mainstream social values, and refrain from disseminating unhealthy and untrue information. For the platform, it should be more self-disciplined and do more self-examination. It should keep in mind social responsibility and promote society main melody while making profits.

In April 2018, Kuaishou added a "Parental Control Mode" on its homepage to limit teenagers screen time. In July of the same year, Douyin announced the launch of the "Sunflower Project"-the first domestic short video platform to focus on the healthy growth of minors. Douyin launched 10 measures at multiple levels including review, product, and content hoping to give every child sunshine, rain and dew. What's more, Kuaishou and Douyin have issued special rectification announcements for illegal live broadcast accounts and content in 2020 .

\subsection{The digital divide makes the inferiors invisible.}

Internet technology and new media has promoted global economy and interaction. Meanwhile, it also posed new challenges to the inferiors - the senior people who can not handle the new technologies, people in poor regions who do not have access to it. All these results in a huge information deficit.

Alvin Toffler, the American future sociologist, noted in his book "Power shift", that the digital divide in information and electronic technology would cause division between developed and underdeveloped countries. 30 years passed, and the truth is that while the developed countries are enjoying the benefits of new technology, the underdeveloped are suffering from info deficit.

Fortunately, more and more people are becoming aware of this problem. In July 2000, WEF (the World Economic Forum) submitted a special report "From Global Digital Divide to Global Digital Opportunity" to the G8 summit. At the APEC meeting held that year, the digital divide became the focus of world attention. On November 24, 2020, the General Office of Chinese State Council issued a notice on the implementation of a plan to help the elderly in the use of new technology.

\section{Conclusion}

With the convergence of medias and rising of new medias, we are entering an information age, enjoying a great "feast" of world life. Some of these "eye candies" are delicious, some of them are delightful, still some deteriorated. "How to deploy our scare resources of attention and not to be overwhelmed by the video flood" is a pressing issue for everyone to think and tackle.

\section{References}

[1] Xiong CY. The definition of new media. http://www.guayunfan.com/baike/106553.html (in Chinese).

[2] Goldhaber MH. The Attention Economy and The Net.

[3] QuestMobile: Report on Chinese mobile internet industry in 2020 http://games.sina.com.cn/y/n/2020-04-22/irczymi77650 35.shtml (in Chinese)

[4] Kaplan AM., Haenlein M. Users of the World, Unite! The challenges and opportunities of social media $[\mathrm{J}]$ Business Horizons, 2010,53 (1):61.

[5] Chatfield T. The attention economy. Economist http://www.360doc.com/content/18/0503/21/7872436 750894735.shtml

[6] Teens and screens. Economist (2018).

[7] Tian H. Analysis of data flow from the perspective of attention economy, 2021(18): 43-46. (in Chinese).

[8] Chen L. Study of the advantages and disadvantages of live-streaming sales [J], Journalism Tide (07);11-13 (2020). (in Chinese). 